\title{
MEDICINE STUDENTS AND EXPOSURE TO ENVIRONMENTAL TOBACCO SMOKE
}

\section{MAGDALENA SZUMSKA ${ }^{1}$, KRYSTYNA TYRPIEŃ ${ }^{1}$, MALGORZATA KOWALSKA ${ }^{2}$, TOMASZ WIELKOSZYŃSKI ${ }^{1}$, and CEZARY DOBOSZ ${ }^{1}$}

\author{
${ }^{1}$ Medical University of Silesia, Zabrze, Poland \\ Department of Chemistry, Faculty of Medicine and Division of Dentistry \\ ${ }^{2}$ Medical University of Silesia, Medical Faculty, Katowice, Poland \\ Department of Epidemiology
}

\begin{abstract}
Objective: Although medicine students express positive attitudes toward providing lifestyle counseling, they require more instruction in many areas of health behavior in order to be helpful to their patients. The presented study included the students' questionnaires analysis regarding their lifestyle and exposure to tobacco smoke. The aim of this study was to examine students' exposure to chosen xenobiotics by determination of selected biomarkers in urine samples, which underlay the basis for exposure assessment towards tobacco smoke. Materials and Methods: The investigated group consisted of first- and second-year medicine students from the Silesian Medical University $(\mathrm{N}=133)$. Data obtained from a questionnaire survey was compared with the results of chosen biomarkers determined in urine samples. The analyses of the main nicotine metabolites were carried out firstly with use of ELISA, followed by the TLC technique with densitometry. Results: According to questionnaires, every third student examined was exposed to passive smoking. The mean concentration of the main nicotine metabolites determined by ELISA in urine samples of smoking students was $1293.52 \pm 396.70 \mu \mathrm{g} / \mathrm{g}$ creatinine. The results of the TLC analysis in the group of smoking students were as follows: for cotinine $-523.10 \pm 68.10 \mu \mathrm{g} / \mathrm{g}$ creatinine and for trans-3'-hydroxycotinine $-653.81 \pm 62.30 \mu \mathrm{g} / \mathrm{g}$ creatinine. Conclusions: Medicine students, regardless of their area of study, are a highly-exposed part of the population to tobacco smoke, not only actively but also passively. Tobacco smoke exposure can be assessed by ELISA as a screening method as well as by more specific TLC technique with densitometry.
\end{abstract}

Key words:

Medicine students, Tobacco, Biomarkers, ELISA, TLC

\section{INTRODUCTION}

The number of civilization-related diseases where neoplastic diseases are the major ones has significantly increased over recent years. Apart from genetics, lifestyle and chemical compounds with their procarcinogenic and carcinogenic influence, food and potable water are the most significant factors that contribute to this rise [1-5]. The synergic effect of air pollution and personal smoking has also been considered as one of those factors [6].

Tobacco smoke is one of the main sources of exposure to carcinogenic and procarcinogenic xenobiotics. It is also regarded as a major external factor that increases oxidative stress in the organism.

This habit concerns not only adults, but young people as well. Among students, smoking is mainly a social phenomenon

This study was a part of research work KNW $-1-009 / \mathrm{N} / 1 / 0$ and KNW-1-135/P/1/0. Received: February 27, 2012. Accepted: November 11, 2012.

Corresponding author: M. Szumska, Department of Chemistry Faculty of Medicine and Division of Dentistry, Medical University of Silesia, Jordana 19, 41-808 Zabrze, Poland (e-mail: mszumska@vp.pl). 
and is a result of preferred and accepted lifestyle. High percentage of the so-called "occasional smokers" (46-50\%) during many social gatherings is disturbing, as it can increase the risk of becoming a regular smoker in the future.

Passive exposure to tobacco smoke, that often takes place during social gatherings, is also the source of free radicals and many toxic substances. It was proven that the concentration of harmful compounds in the sidestream is higher than in the mainstream inhaled by a smoker and many young people are not aware of that [7].

Another problem is that the chosen major of study does not influence the decision taken by students concerning smoking, since there are just minor differences in the numbers of smoking students of medical and non-medical faculties [8]. Although medical students express positive attitudes toward providing lifestyle counseling, they require more instruction in the areas of weight screening, nutrition, other health behaviors (passive or active smoking) and physical activity recommendations in order to be helpful to their future patients $[8,9]$.

The cotinine assays are mainly used for biochemical verification of the smoking status [10-12], but it was proven that trans-3'-hydroxycotinine could be considered the main nicotine metabolite in urine samples [13]. Moreover, Benowitz et al. stated that the nicotine metabolites ratio could be used as a predictor of cigarette consumption [14]. The evaluation of xenobiotics exposure is often carried out by the immunochemical technique [15-17], however the chromatographic techniques are more popular due to their higher specificity $[16,18]$. Thin layer chromatography has been rarely used for this purpose (only to determine cotinine) [11], but the LC-MS/MS technique is frequently applied in this area [18].

The aim of the presented study was the assessment of exposure to chosen xenobiotic biomarkers in a group of young medical students from the Medical University of Silesia in Katowice, Faculty of Medicine in Zabrze. The cross-sectional study was conducted with the use of the questionnaire regarding the students' lifestyle and knowledge concerning xenobiotics.

The study involved collecting students' urine samples to examine their exposure to chosen xenobiotics by the use of immunoassay (ELISA) as the screening method for the assessment of tobacco smoke exposure, followed by TLC with densitometry for the evaluation of the main nicotine metabolites in the urine samples.

\section{MATERIALS AND METHODS}

\section{Study population}

The investigated group included first- and second-year medicine students from the Silesian Medical University ( $\mathrm{N}=133$ ). The anonymous, self-completed questionnaire concerning environmental exposure to xenobiotics (mainly tobacco smoke exposure), lifestyle and eating habits was given to students who were willing to take part in the research. The survey consisted of 24 questions regarding the issue of passive and active smoking, the age when they used cigarettes for the first time, knowledge of harmful effects of tobacco, health attitudes etc.

Out of 133 students who filled the questionnaire, 85 provided urine samples for further analysis. In the study group, 40 students were active smokers and the control group consisted of 45 non-smokers. The group of non-smokers was divided into groups of the exposed $(\mathrm{N}=25)$ and the nonexposed $(\mathrm{N}=20)$ persons to environmental tobacco smoke. The project was accepted by the Local Committee for Animal Research (opinion No. 2/04 of 13 January 2004 and resolution No. 27/2007 of 17 April 2007) as well as by the Local Ethics Committee of the Medical University of Silesia (NN-6501-49/I/06).

\section{Chemicals}

Solvents of analytical grade were used as eluents for spectroscopy or for HPLC (dichloromethane - DCM, acetonitrile; Baker, Fluka) as well as for extraction and separation procedures. 
Nicotine metabolites standards: (-)-cotinine (1-methyl5-[3-pyridyl]-2-pyrrolidinone) was delivered by Sigma Aldrich, and trans-3'-hydroxycotinine was obtained from Toronto Research Chemicals Inc. (Ontario, Canada). Non-polar resin Amberlite XAD-2 was delivered by Supelco, sodium hydroxide, acetone and other reagents were purchased from local commercial sources (POCh - Gliwice, Poland).

\section{TLC analysis}

Nicotine metabolites were analyzed in urine by the use of the procedure described above [19].

Urine samples were adjusted to $\mathrm{pH}>10$, and shaken with portions of Amberlite XAD-2 for 5 min and centrifuged at $2000 \mathrm{~g}$ for $10 \mathrm{~min}$. The fraction containing nicotine and its metabolites was isolated by shaking twice with $5 \mathrm{ml}$ of acetone with dichloromethane $(1+3, v / v)$. Then, the organic phase was transferred to a fresh tube to evaporate to dryness under nitrogen stream. Residue was dissolved in dichloromethane and analyzed by TLC-densitometry. TLC separations were performed on chromatographic plates coated with C18 stationary phase (Machery Nagel, Düren, Germany) and in a horizontal chamber (DSII Chromdes, Lublin, Poland). Mobile phase: acetonitrilewater $(88+12, \mathrm{v} / \mathrm{v})$ with addition of sodium 1-octanesulfonate. Visualization was carried out under UV illumination at $\lambda=254 \mathrm{~nm}$. Next, the spots were quantified by scanning in reflectance (UV absorbance at $\lambda=260 \mathrm{~nm}$, zigzag scanning mode) using a CS 9301 PC scanner (Shimadzu).

\section{ELISA determination}

Nicotine metabolites were analyzed in urine with the use of competitive ELISA method described in the article written by Wielkoszyński et al., 2009 [15]. The specific antibody was coated on ELISA plates after immunopurification on cotinine-Sepharose column. The plates were incubated simultaneously with urine/cotinine standards and horseradish peroxidase (HRP) - conjugated of cotinine.
The plates were washed after 12-h incubation and solid phase - bound HRP activity was measured $\left(\mathrm{TMB} / \mathrm{H}_{2} \mathrm{O}_{2}\right.$ as substrate). Then, the reaction was stopped with $0.5 \mathrm{M}$ sulfuric acid and optical density was measured at $\lambda=405 \mathrm{~nm}$ (at $\lambda=630 \mathrm{~nm}$ as reference wavelength, PowerWaveXS plate reader - BioTek, USA).

The coefficients of variation ranged from 4.4 to 8.7 for the ELISA method, which proved the high analytical precision of assay results and the stability of the applied method [15].

\section{Statistical analysis}

Statistical analyses were performed with the use of procedures available in the Statistica 8.0 software. The differences between the concentrations of particular metabolites in the exposed and non-exposed subjects were calculated by the U-Mann Whitney test, and the differences between qualitative variables were calculated by the chi-square test.

The association between the concentrations of nicotine metabolites obtained with the ELISA technique and the sum of cotinine metabolites with the TLC technique was examined with the use of Pearson correlation coefficient. The interpretation of statistical significance of the results was based on the criterion $\mathrm{p}<0.05$.

\section{RESULTS}

The criteria (based on the concentration of the main nicotine metabolites detected by ELISA in urine samples) for exclusion or inclusion to the group of smokers and nonsmokers were as follows:

- smokers: $>200 \mu \mathrm{g} / \mathrm{g}$ creatinine,

- non-smokers: $<200 \mu \mathrm{g} / \mathrm{g}$ creatinine.

Moreover, in order to select passive smokers from the non-smokers group, the following criteria were applied:

- passive exposure to tobacco smoke: 20-200 $\mu \mathrm{g} / \mathrm{g}$ creatinine, 
Table 1. Descriptive statistics of the study group and chosen determinants of their lifestyle

\begin{tabular}{lcccc}
\hline \multicolumn{1}{c}{ Variable } & $\begin{array}{c}\text { Female } \\
(\mathrm{N}=76)\end{array}$ & $\begin{array}{c}\text { Male } \\
(\mathrm{N}=57)\end{array}$ & $\mathrm{p}$ & $\begin{array}{c}\text { Total } \\
(\mathrm{N}=133)\end{array}$ \\
\hline Age (years) $(\mathrm{M} \pm \mathrm{SD})$ & $20.7 \pm 0.9$ & $20.4 \pm 0.9$ & $0.01^{*}$ & $20.6 \pm 0.9$ \\
Age of smoking initiation (years) $(\mathrm{M} \pm \mathrm{SD})$ & $15.3 \pm 2.4$ & $15.3 \pm 2.6$ & $0.80^{*}$ & $15.3 \pm 2.5$ \\
$\begin{array}{l}\text { Smoking status [n (\%)] } \\
\quad \text { current smoking }\end{array}$ & $34(44.7)$ & $26(45.6)$ & $0.90^{* *}$ & $60(45.1)$ \\
$\quad$ passive smoking & $26(34.2)$ & $16(28.5)$ & $0.40^{* *}$ & $42(31.6)$ \\
$\quad$ current smoking $\geq 10$ cigarettes per day & $10(13.1)$ & $4(7.0)$ & $0.20^{* *}$ & $14(10)$ \\
Drinking [n $(\%)]$ & & & & \\
$\quad$ tea & $74(97.4)$ & $55(96.5)$ & $0.70^{* *}$ & $129(97.0)$ \\
$\quad$ coffee & $56(73.7)$ & $47(82.5)$ & $0.20^{* *}$ & $103(77.4)$ \\
$\quad$ alcohol & $50(65.8)$ & $36(63.1)$ & $0.70^{* *}$ & $86(64.7)$ \\
Using marihuana ever [n $(\%)]$ & $5(6.5)$ & $1(1.7)$ & $0.10^{* *}$ & $6(4.5)$ \\
\hline
\end{tabular}

$\mathrm{M}$ - mean concentration value; $\mathrm{SD}$ - standard deviation.

* Statistical significance in the U-Mann Whitney test.

** Statistical significance in the chi ${ }^{2}$ test.

- non-exposed to passive smoking: $<20 \mu \mathrm{g} / \mathrm{g}$ creatinine. that group were women. According to the data obtained

The characterization of the study group is presented in Table 1.

The mean age of cigarette smoking initiation was $15.3 \pm 2.5$ years. Nearly half of the study group declared active smoking (45.1\%, where $44.7 \%$ were women and 45.6 were men); $10 \%$ of the examined population declared smoking more than 10 cigarettes per day and over $70 \%$ of from the questionnaire, every third student examined $(31.3 \%)$ was exposed to passive smoking. Almost all interviewed students $(96.4 \%)$ were aware of the harmful influence of cigarette smoking and in most cases this knowledge was based on information obtained at school (93.4\%).

According to the questionnaire results, $62.8 \%$ of the examined students declared alcohol consumption.

Table 2. Nicotine metabolites determined in urine of the examined passively smoking students

\begin{tabular}{cccc}
\hline & \multicolumn{3}{c}{$\begin{array}{c}\text { Passive exposure to environmental tobacco smoke } \\
(\mathrm{N}=45)\end{array}$} \\
\cline { 2 - 4 } $\begin{array}{c}\text { Analyzed } \\
\text { biomarker }\end{array}$ & $\begin{array}{c}\text { yes } \\
(\mathrm{N}=25) \\
(\mathrm{M} \pm \mathrm{SD})\end{array}$ & $\begin{array}{c}\text { no } \\
(\mathrm{N}=20) \\
(\mathrm{M} \pm \mathrm{SD})\end{array}$ & $\mathrm{p}^{*}$ \\
\hline $\begin{array}{c}\text { Nicotine metabolites (ELISA) } \\
(\mu \mathrm{g} / \mathrm{g} \text { creatinine) }\end{array}$ & $80.60 \pm 33.70$ & $18.99 \pm 3.72$ & 0.001 \\
Cotinine (TLC) $(\mu \mathrm{g} / \mathrm{g}$ creatinine $)$ & $40.89 \pm 24.80$ & n.d. & - \\
$\begin{array}{c}\text { Trans-3'-hydroxycotinine (TLC) } \\
(\mu \mathrm{g} / \mathrm{g} \text { creatinine })\end{array}$ & $60.79 \pm 46.70$ & n.d. & - \\
\hline
\end{tabular}

* p value in the U-Mann Whitney test.

n.d. - not detected.

Other abbreviations as in Table 1. 
Table 3. Nicotine metabolites determined in urine of the examined actively smoking students and passively smoking students

\begin{tabular}{|c|c|c|c|}
\hline $\begin{array}{l}\text { Analyzed } \\
\text { biomarker }\end{array}$ & $\begin{array}{l}\text { Passive exposure to tobacco } \\
\text { smoke } \\
(\mathrm{N}=25) \\
(\mathrm{M} \pm \mathrm{SD}) \\
\end{array}$ & $\begin{array}{l}\text { Active exposure to tobacco } \\
\text { smoke } \\
(\mathrm{N}=40) \\
(\mathrm{M} \pm \mathrm{SD})\end{array}$ & $\mathrm{p}^{*}$ \\
\hline $\begin{array}{l}\text { Nicotine metabolites (ELISA) } \\
(\mu \mathrm{g} / \mathrm{g} \text { creatinine })\end{array}$ & $80.60 \pm 33.70$ & $1293.52 \pm 396.70$ & 0.001 \\
\hline Cotinine (TLC) ( $\mu \mathrm{g} / \mathrm{g}$ creatinine) & $40.89 \pm 24.80$ & $523.10 \pm 68.10$ & 0.003 \\
\hline $\begin{array}{l}\text { Trans-3'-hydroxycotinine (TLC) } \\
\text { ( } \mu \mathrm{g} / \mathrm{g} \text { creatinine) }\end{array}$ & $60.79 \pm 46.70$ & $653.81 \pm 62.30$ & 0.001 \\
\hline
\end{tabular}

Abbreviations as in Table 1 and 2.

Table 4. Nicotine metabolites concentration and statistical significance of the gender difference according to the U-Mann Whitney test

\begin{tabular}{cccc}
\hline $\begin{array}{c}\text { Analysed } \\
\text { biomarker }\end{array}$ & $\begin{array}{c}\text { Female } \\
(\mathrm{N}=48) \\
(\mathrm{M} \pm \mathrm{SD})\end{array}$ & $\begin{array}{c}\text { Male } \\
(\mathrm{N}=37) \\
(\mathrm{M} \pm \mathrm{SD})\end{array}$ & $\mathrm{p}^{*}$ \\
\hline Nicotine metabolites $(\mu \mathrm{g} / \mathrm{g}$ creatinine) & $820.09 \pm 268.33$ & $237.22 \pm 117.12$ & 0.05 \\
\hline
\end{tabular}

Abbreviations as in Table 1 and 2.

Among the investigated group $(\mathrm{N}=133)$, in $48 \%$ of the examined population, nicotine metabolites were detected in urine samples. The analyses were carried out with the use of ELISA and the TLC technique. The results are presented in Tables 2-4.

The mean cotinine recovery values for the urine were $88.56 \pm 11.38 \%$ and the within-run and between-run coefficients of variation $(\mathrm{CV})$ for the ELISA method were between 4.4-11.3\%, whereas these values for TLC equaled $80 \%$ (mean recovery) and $9.2 \%(\mathrm{CV})$, respectively.

The study analyses included determination of the main nicotine metabolites by means of ELISA (mean concentration of the main nicotine metabolites in urine samples in the investigated group of students was $464.37 \pm 144.71 \mu \mathrm{g} / \mathrm{g}$ creatinine), as well as by the TLC technique coupled with densitometric analysis (mean concentration in the urine samples for cotinine - 281.9946.45 and for trans3'hydroxycotinine - $357.30 \pm 54.50 \mu \mathrm{g} / \mathrm{g}$ creatinine) (Table 3). The correlation coefficients for the nicotine metabolites determination obtained by ELISA and the TLC technique with densitometry were calculated and presented in Figure 1.

The concentrations of selected biomarkers and statistical significance of the smoking status or gender difference according to the U-Mann Whitney test are presented in Tables 2-4.

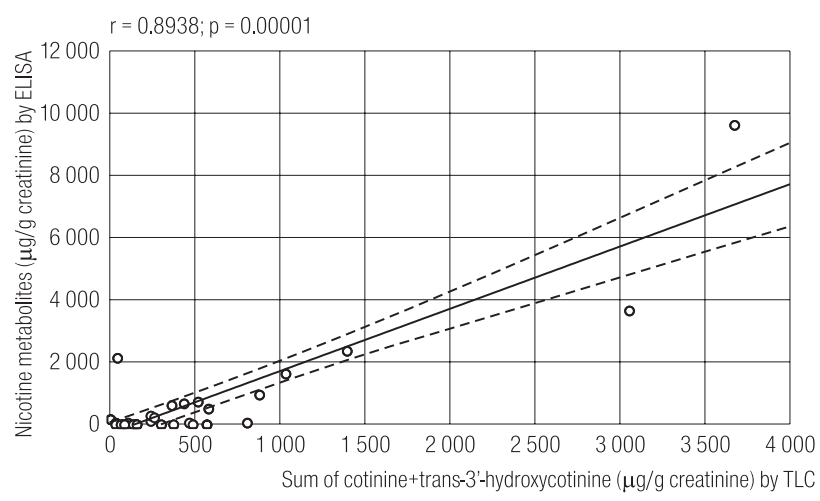

Fig. 1. Correlation between the sum of the main nicotine metabolites concentrations determined by TLC and nicotine metabolites concentrations determined by the ELISA technique 


\section{DISCUSSION}

The data obtained from the questionnaire survey showed quite a high percentage of young smokers, and what is more these are young people who choose to be physicians in the future. This means that most of these students do not combine their lifestyle as well as attitudes towards health with the faculty they have chosen and the future career paths. The percentage of medical students exposed to tobacco smoke in the Silesia region is one of the highest in Europe and is similar to the results obtained in Albania (44.3\%), Greece (41\%), Spain (42\%) and Croatia $(36.3 \%)[8,20]$. Legal abusive substances such as nicotine, alcohol, and caffeine facilitate an exponential increase in addictive behavior, denial, and other psychological disorders. Many natural popular substances, such as marijuana, are taken by students to improve their learning ability [10]. Among the tested medicine students, 6 of them (4.4\%) admitted to taking one of the most popular drugs, namely marihuana. The immunochemical methods, like the ELISA technique, allow fast and less laborious evaluation of the nicotine exposure based on the sum of nicotine metabolites. In immunochemical methods, the estimation of exposure is determined by cross-reactivity of nicotine metabolites with applied specific antibodies and for this reason this method is useful rather as a screening tool.

In the presented study, the ELISA technique was used as the screening method for the evaluation of tobacco smoke exposure. This method showed high positive correlation with the results of TLC and proved to be an excellent screening tool $(\mathrm{r}=0.89)$.

Based on the obtained results, it can be concluded that the potential exposure to environmental xenobiotics, such as tobacco smoke components, is similar in the group of male and female medical students, although a higher percentage of young women were smoking more than 10 cigarettes per day. Many studies show that nowadays young women smoke more compared to their mothers and, unfortunately, the number of young female smokers is increasing [20].

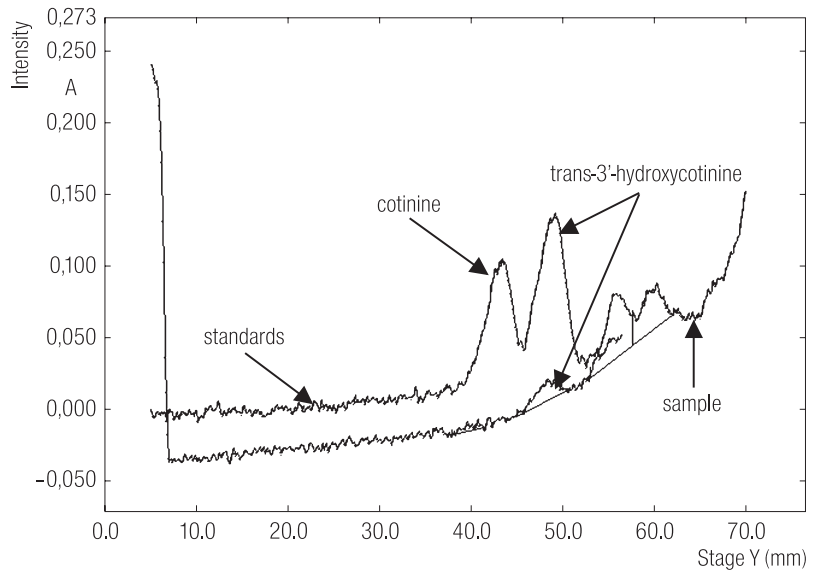

The separation was carried out in C18/acetonitrile-water $(88+12$, v/v; with $50 \mathrm{mg}$ of sodium 1-octanesulfonate $/ 100 \mathrm{ml}$ ) chromatographic system; $\lambda=254 \mathrm{~nm}$.

Fig. 2. Densitogram of the urine extract from the student who declared to be of the non-smoking status and in which trans-3'-hydroxycotinine was identified by TLC with densitometry

The study results showed that the level of determined biomarkers corresponded with the questionnaire data about active and passive smoking. The example of the TLC densitogram of urine extract from a student who declared to be of the non-smoking status was presented in Figure 2. The presence of trans-3'-hydroxycotinine in this student's urine sample proves recent passive exposure to environmental tobacco smoke. The issue of passive smoking and its health consequences for young people, especially students, is often belittled. Very often they are not aware that substances presented in sidestream smoke are sometimes even more harmful than these in the mainstream smoke.

The highest concentrations of biomarkers were determined in the urine of students smoking 10 or more cigarettes per day.

The dominant metabolite determined in the students' urine samples was trans-3'-hydroxycotinine, which was confirmed by the main nicotine metabolites molar ratio. Trans-3'hydroxycotinine was detected in approximately $97 \%$ of all analyzed samples of the exposed students. The molar ratio 
was $>1$ in the significant majority (64\%) of samples where two main nicotine metabolites were present.

\section{CONCLUSIONS}

Medicine students, regardless of their area of study, seem to be a part of the population significantly exposed to tobacco smoke, not only actively but also passively. This phenomenon was also confirmed by other authors who showed that in some countries the number of smoking future physicians was close to or even exceeded $50 \%$ of the examined population [8].

The passive exposure can significantly increase oxidative stress parameters and young people exposed to environmental tobacco smoke are often not aware of the fact that frequent passive exposure may lead to significant increase in cancer risk.

Immunochemical methods like ELISA can be applied as the screening method for the assessment of tobacco smoke exposure. However, for a more specific evaluation, chromatographic methods are more suitable.

Modern planar chromatography with densitometry is a relatively simple and economical method to determine biomarkers of tobacco smoke exposure in body fluids. This technique can be used to verify the data on the smoking status collected from questionnaires. TLC with densitometry may not only be a useful technique in the determination of toxic substances in the environment, but also in the metabolic investigations of substances dangerous to human health.

The applied questionnaire proved to be a reliable source of information regarding the tobacco smoke exposure in the group of young adults. It is worth considering creating the adequate educational programs that could help students who declared active smoking to quit this habit or at least raise their awareness of how to prevent or reduce the side effects of exposure to tobacco smoke, for example by antioxidant supplementation.

\section{REFERENCES}

1. Ottawa Chapter for Health Promotion. Oxford: Oxford University Press; 1987.

2. Center for Disease Control and Prevention. Third National Report of Human Exposure to Environmental Chemicals. Atlanta: Department of Health and Human Services, CDC; 2005.

3. Torikaiu K, Uwano Y, Nakamori T, Tarora W, Takahashi H. Study on tobacco components involved in the pyrolytic generation of selected smoke constituents. Food Chem Toxicol 2005;43:559-68.

4. Barnoya J, Glantz SA. Cardiovascular effects of secondhand smoke - Nearly as large as smoking. Circulation 2005;111:2684-98.

5. Tonstad S, Svendsen M. Premature coronary heart disease, cigarette smoking, and the metabolic syndrome. Am J Card 2005;96:1681-5.

6. Peled R. Air pollution exposure: Who is at high risk? Atmos Environ 2011;45:1781-5.

7. Dvorak RD, Simons JS. Affective differences among daily tobacco users, occasional users, and non-users. Addict Behav 2008;33:211-6.

8. Smith DR, Leggat PA. An international review of tobacco smoking among medical students. J Postgrad Med 2007;53:55-62.

9. Warren CW, Jones NR, Eriksen MP, Asma S. Patterns of global tobacco use in young people and implications for future chronic disease burden in adults. Lancet 2006;367:749-53.

10. Fidler JA, West R, Jarvis MJ, Wardle J. Early dating predicts smoking during adolescence: A prospective study. Addiction 2006;101:1805-13.

11. Man CN, Fathelrahman AI, Harn GL, Lajis R, Samin ASM, Omar M, et al. Correlation between urinary nicotine, cotinine and self-reported smoking status among educated young adults. Environ Toxicol Pharmacol 2009;28:92-6.

12. Zielinska-Danch W, Wardas W, Sobczak A, SzoltysekBoldys I. Estimation of urinary cotinine cut-off points distinguishing non-smokers, passive and active smokers. Biomarkers 2007;12:484-96. 
13. Matt GE, Quintana PJE, Liles S, Hovell MF, Zakarian JM, Jacob P, et al. Evaluation of urinary trans-3'-hydroxycotinine as a biomarker of children's environmental tobacco smoke exposure. Biomarkers 2006;11:507-23.

14. Benowitz NL, Jacob P. Trans-3'-hydroxycotinine: Disposition kinetics, effects and plasma levels during cigarette smoking. Br J Clin Pharmacol 2001;51:53-9.

15. Wielkoszynski T, Tyrpien K, Szumska M. The enzymelinked immunosorbent assay (ELISA) method for nicotine metabolites determination in biological fluids. J Pharm Biomed 2009;49:1256-60.

16. Dhar P. Measuring tobacco smoke exposure: quantifying nicotine/cotinine concentration in biological samples by colorimetry, chromatography and immunoassay methods. J Pharm Biomed 2004;35:155-68.

17. Schneider RJ. Environmental immunoassays. Anal Bioanal Chem 2003;375:44-6.
18. Miller EI, Norris HRK, Rollins DE, Tiffany ST, Wilkins DG. A novel validated procedure for the determination of nicotine, eight nicotine metabolites and two minor tobacco alkaloids in human plasma or urine by solid-phase extraction coupled with liquid chromatography-electrospray ionization-tandem mass spectrometry. J Chromatogr B 2010;878:725-37.

19. Tyrpień K, Wielkoszyński T, Janoszka B, Dobosz C, Bodzek D, Steplewski Z. Application of liquid separation techniques to the determination of the main urinary nicotine metabolites. J Chromatogr A 2000;870:29-38.

20. Viswanathan B, Warren CW, Jones NR, Asma S, Bovet P. Linking Global Youth Tobacco Survey (GYTS) data to the WHO framework convention on tobacco control (FCTC): The case for the Seychelles. Prev Med 2008;47:S33-7.

This work is available in Open Access model and licensed under a Creative Commons Attribution-NonCommercial 3.0 Poland License - http://creativecommons.org/ licenses/by-nc/3.0/pl/deed.en. 